\title{
An Assistive Computerized System with Tangible User Interfaces for Children with Moderate Intellectual and Learning Disabilities
}

\author{
$\underline{\text { doi:10.3991/ijet.v6iS2.1640 }}$ \\ J.M. Alja'am ${ }^{1}$, A.M. Jaoua ${ }^{1}$, S. Alhazbi ${ }^{1}$, A. Hasnah ${ }^{1,2}$, A. Karime ${ }^{3}$ and A. Elsaddik ${ }^{3}$ \\ ${ }^{1}$ Qatar University, Doha, Qatar \\ ${ }^{2}$ Qatar Foundation, Education Division, Doha, Qatar \\ ${ }^{3}$ University of Ottawa, Ottawa, Canada
}

\begin{abstract}
In this paper we propose an assistive learning system for children with moderate intellectual and learning disabilities that supports collaboration, data exploration, communication and creativity. The system offers a wide range of tutorials on basic concepts of elementary sciences with some edutainment games and puzzles based on different tangible user interfaces TUIs. The system can enhance the communications, memorization, reasoning and learning capabilities of the children with special needs. The tutorials contain multimedia elements that help the children understand effectively the topics and allow them to interact and be more proactive. An assessment component is developed to evaluate the children understanding. Parents are actively involved in the learning process by being able to add or customize contents specific to their children. The children can use the TUIs alone and get prompted on all the steps to perform some daily activities like the school day activity, the tooth brushing activity, etc. This will increase their selfreliance and self-dependence.
\end{abstract}

Index Terms-Assistive Learning Tools, Educational Software, Tutorials Design, Learning Disability, Special Needs, Edutainment.

\section{INTRODUCTION}

Intellectual disability is characterized both by a significantly below-average score on a test of mental ability or intelligence and by limitations in the ability to function in areas of daily life, such as communication, self-care, and getting along in social situations and school activities. Intellectual disability is sometimes referred to as a cognitive disability or mental retardation. Children with intellectual disability can and do learn new skills, but they develop more slowly than children with average intelligence and adaptive skills. There are different degrees of Intellectual disability, ranging from mild to profound. A person's level of Intellectual disability can be defined by their intelligence quotient, or by the types and amount of support they need. Developmental disabilities begin anytime during development up to 22 years of age and usually last throughout a person's lifetime [5][15].

Children with developmental disabilities can have different problems with many everyday learning activities. They can be helped in different ways to learn if they are given suitable support, different learning materials, or even just some encouragement. Their difficulties can cover all aspects of life and learning and affect their per- formance in almost everything they do. Others will have very specific difficulties, for example, someone with dyslexia may have a problem with writing and reading or even with just one aspect of spelling. This type of difficulty may just affect their performance in spelling alone, or may have caused other problems by delaying their development of writing skills.

Conducting research and developing software and tools for people with disability is a challenging task. Few individual research projects are carried out in the Arab world, and the obtained results are still moderate [1]. Many special needs instructors have individually developed Arabic tutorials for children with disabilities. However, these educative tutorials are very primitive with low attractiveness. They are developed mainly in Microsoft Power Point software with low quality images. In addition, most of the Arabic software engineering companies do not develop educational software for special users because they do not see great financial benefits from this market even though $10 \%$ of the population around of the world are living with some kind of disability. This rate is expected to increase in the coming ten years to exceeds $15 \%$. One study estimates that $3.73 \%$ of Saudis have intellectual disabilities [1]. No accurate, official, and up-to-date statistics are given about people with disabilities in the Middle East and North Africa region (MENA region). However, the following note [7] gives a good survey about people with disability in the MENA region. It states that the high burden of disability on the development of countries in the MENA region will increase over the next two decades. In addition, integrating individuals with disabilities into all aspects of social and economic life, including education, vocational rehabilitation and employment, will benefit not only the individual, but the society in general. The Educational systems in the MENA region continue to exclude the majority of the disabled school-aged population at the primary level and almost the entirety of this population at the university level. The survey given in [7] reveals that the range of prevalence is between 1 and 10 percent of the population. And for ten countries of the MENA, which comprise a total of 250 million people, the range of people with disabilities is estimated between 9 and 27 million people.

We mention that the number of registered people with disability in the state of Qatar is 5,378 where 3,285 are males and 2,120 are females. There are 1,556 mentally-ill, 
632 deaf, 358 blind, and 2773 of other handicaps (source: Qatar Statistics Center - Report - 2007).

Number of important research projects for people with special needs has been developed recently. We mention the following projects: AmlVital project [4] launched at the University of Granada (2007) creates devices for the elderly and disabled people. Archimedes project [14] promises accessible technology for the disabled. Chelin et al. [6] proposed a system that uses natural language to assist visually handicapped people in writing compositions. Alper and Raharinirina [3] reviewed literature on assistive technology for people with disabilities and offer guidelines for future researchers in this area. First, each student should be given an individual assessment before the assistive technology is given to him. The student's needs and features must be taken into account as people with disability are different in terms of understanding, intelligence and limitations. Second, family involvement in the learning process is critical if the student is to gain maximum benefit from the technological assistive system. Third, studies should build in a period of maintenance and generalization, particularly with the development of software for students with intellectual disabilities. Jemni and Elghoul [9] presented an untested web based tool called WebSign that translates text to sign language. ALFakheer from King Saud University has announced recently the development of an educative web-based tool entitled FAHEEM for children with Autism. However, this tool is still in the testing phase and we don't know yet its effectiveness. Different types of inclusive education policies and programs are starting to emerge in some of the countries in the region, mainly as part of national quality enhancement agendas or educational strategic plans. However, these efforts remain limited in scope [7].

An extensive literature survey is conducted in [13] on research from 1990 till 2005, on assistive technology as a self-management tool for prompting students with intellectual disability to initiate and complete daily tasks. She mentioned that, "although Kimball, Kinney, Taylor and Stromer $(2003 ; 2004)$ outline instructions on how to create computer-based activity schedules with photographs and video models using MS-Power Point, to date no research base exists to support this new and creative use of high tech systems in providing students with visual, auditory, and animated cues for following and transitioning between activities or use in other forms of selfmanagement". Based on this conclusion, we propose an assistive learning system that use multimedia elements to assist the children with intellectual challenges to understand concepts of living and of basic elementary sciences, and strengthen their self-reliance and independence. Different tutorials are developed with contents based on local environments. They are complemented by attractive edutainment games and puzzles where the children can interact with the system and learn in a fun manner.

The remainder of the paper is organized as follows. Section 2 introduces the Shafallah center for children with special needs in Doha, Qatar. It also discusses briefly the heavy load on the center and the current model of learning. Section 3 presents the project's main objectives, Section 4 discusses the project's main tasks, Section 5 describes briefly the tutorials topics, Section 6 discusses the different tangible user interfaces that can be used by the children to be more proactive during the learning session, Section 7 shows how to extract keywords from plain text and link them with images, clips and sounds. This feature will allow the children with mild intellectual disability to surf the Internet and understand the text in the websites. Section 8 presents the evaluation techniques of the proposed systems as well as the tutorials and the edutainment games, and finally Section 9 draws the conclusion and our future work.

\section{SHAFALLAH CENTER FOR CHILDREN WITH SPECIAL NEEDS IN DOHA QATAR}

The Shafallah Center for children with special needs in Doha, Qatar was established by the effort and under the authority of the chairperson of the supreme council of family affairs, Sheikha Mozah Bint Nasser Bin Abdullah AL-Missned, the Emir of Qatar's wife. The center offers comprehensive services and care to individuals with developmental learning challenges, their families, and the community. The center provides educational and related services to children of both genders from the age of three to twenty-one, addressing all developmental disabilities including: vocational education, rehabilitation (speech and language pathology, occupational therapy, physiotherapy, adoptive physical education and therapy), pediatrics, child and adolescent psychiatry, psychological services (cognitive assessment, behavior analysis, family counseling, music therapy, play therapy) social work and family support. The center has different units/schools to deal with children with special needs of different levels and categories. The school units of the Shafallah center are the following:

\section{A. School Unit 1}

This program provides care for children aged six to fourteen years, with moderate learning challenges. It includes special education coursework in pre-academic, academic and pre-vocational areas. The curriculum emphasizes social and daily-life skills.

\section{B. School Unit 2}

Students with moderate and severe intellectual disabilities, aged six to twenty-one years, are catered for in this unit. To increase independence, teaching combined with assistive technology is centered upon activities of daily living such as self-care and basic communication. At the same time, socialization and leisure education are emphasized to increase quality of life.

\section{Autism Unit}

This program is designed for students diagnosed with autism spectrum disorders, whose ages range between six and twenty-one years. These students learn best with a structured teaching model such as TEACCH (Treatment and Education of Autistic and Related Communication Handicapped Children). Other special methods such as discrete trial training and highly visual communication systems are also tailored for these children.

\section{Vocational Training Unit}

This unit serves students aged fourteen to twenty-one years. The program aims at matching a suitable job to every adolescent or young adult through evaluating the students' interests and abilities and encouraging exposure to multiple job experiences, with specialization as the ideal result. 
Dealing with children with special needs requires a lot of resources, time and efforts. In fact, between two and three special education instructors are needed in every learning session of seven to eight children. The ratio is 1 instructor for 2.5 children. In addition, there is an individual learning plan, set by the special education instructors, for every child in the learning session. The study plan is updated continuously based on the child's progress. The instructors are also repeating the same lessons during the learning sessions and in almost every day and week as the children cannot remember their lessons easily. In addition, children are fully relying on the instructors who currently apply the classical one-way learning model shown in Fig. 1 , where teachers possess the experience and knowledge and the students are just receiving the information and repeating what the teachers are saying and instructing.

The Shafallah center is currently accommodating around 500 children with special needs and there is a plan to increase this number in the very near future. Hundreds of other children with SP are still in waiting lists. However, the center organizes regular workshops for parents to help them tacking care of their children at home.

\section{PROJECT OBJECTIVES AND CONTRIBUTIONS}

Our focus in this research project is to develop an Arabic-based tutorials system to enhance the communication capabilities of children with moderate intellectual and learning disabilities who are resident in the Shafallah center for children with special needs in Doha, Qatar. The main objectives of our project can be summarized as follows.

\section{A. Tutorials Design}

To develop Arabic-based tutorials system for children with moderate intellectual disability (MID) and those with moderate learning disability (MLD). We can then unveil the hidden potential within these children and improve their skills. They can be reintegrated in normal schools and compete with their peers. The tutorials give short and simple Arabic sentences with clips, images and sounds. Some features will be added like words prediction and abbreviation expansion based on the work done in [9]. Whenever the children begin to type a word, the system displays a list of frequently used words that begin with those letters. The children can select the appropriate word (or image) from the display. We can then improve the writing skills of these children.

\section{B. Edutainment Puzzlez and Games}

To enhance the reasoning and memorization skills of children with MID-MLD. We propose to develop some puzzles and edutainment games of different levels associated with the tutorials. Once the children learn a lesson, they will be asked to solve the corresponding puzzles and play with the associated games.

\section{Parents Involvement in the Learning Process}

To involve parents in the learning process in addition to teachers. The system allows parents and teachers to add and update contents specific to the children according to predefined rules. Involving parents in the learning process contributes positively in improving the skills of children with MID-MLD and help them acquire academic skills more easily so that they can take pride in themselves as shown in [2]. In fact, the school day is limited and if the

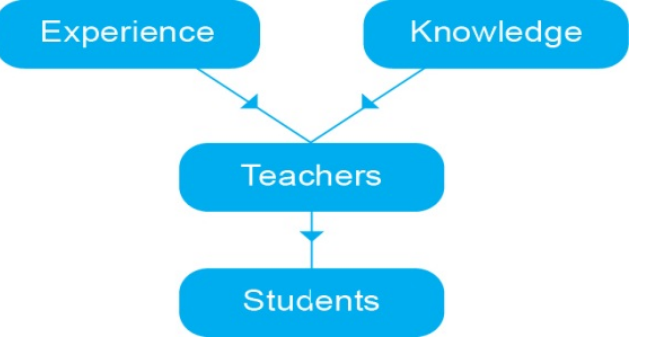

Figure 1. The one-way classical learning model where teachers who possess knowledge and experience are feeding the students.

children can use the software at home, there is a greater possibility of use. Parents can use our proposed interface given in [2].

\section{Understanding Text}

To assist the children with MID-MLD improve their understanding of electronic text (and dialogue). We propose some computing techniques to extract keywords from electronic text (i.e., web sites) using concepts analysis. We associate then these keywords with images, sounds and clips that would be displayed to the children to enhance their understanding.

\section{PRoject Main TASKS}

\section{A. Set and Design the User Interface}

Any successful computerized system should have an easy to use interface that facilitates its usage. Thus the system should possess an attractive interface that is suitable to the potential users. The interface will be tested by its users and updated whenever necessary. Different tangible user interfaces are proposed: (1) Magic Stick [9], (2) Foot Learn-Pad [12] and (3) Lenovo IdeaPAD [2].

\section{B. Contents Development}

To develop the contents which are suitable to the children with MID-MLD. The contents should be attractive by using multimedia elements. The advantages of a multimedia content are: (1) It is an audiovisual and interactive medium and help creativity; (2) The treatment or situation can be reproduced; (3) It can be adjusted to the individual needs; (4) It has an effect on more than one sense, and can be more effective.

\section{Design of Simple Questions/Answers tools, New Puzzles and Edutainment Games}

These tools will help the children improving their reasoning and memorization skills. Intelligent algorithms are used to guide the children in their selection of the moves and to converge always towards the solution. For example, after learning the daily morning activities, the children will be asked to solve some specific related puzzles, for instance how to initiate and complete the brushing activity. The images will be presented randomly on the screen and the children will be asked to arrange them in the right order. If the child selects the toothbrush image it will go automatically to the first position. The child will see it moving slowly to the right position (drag-and-drop, selectand-move) and will be encouraged to complete the activity. If the child selects a wrong image, it will not fit in the desired position. If the child failed to select the right images after three attempts, some hints will be displayed to screen to select the right image. Table I shows the tooth 
TABLE I.

TOOTH BRUSHING TASKS DISPLAYED RANDOMLY

\begin{tabular}{|c|c|c|c|c|}
\hline $\begin{array}{c}\text { frac } \\
\begin{array}{c}\text { brush } \\
\text { teeth }\end{array}\end{array}$ & $\begin{array}{c}\text { put on } \\
\text { toothpaste }\end{array}$ & dry mouth & toothbrush & toothpaste \\
\hline
\end{tabular}

TABLE II.

TOOTH BRUSHING ACTIVITIES DISPLAYED RANDOMLY

\begin{tabular}{|c|c|c|c|c|}
\hline IIII & 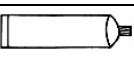 & पim? & & 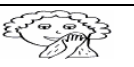 \\
\hline toothbrush & toothpaste & $\begin{array}{l}\text { put on } \\
\text { toothpaste }\end{array}$ & $\begin{array}{l}\text { brush } \\
\text { teeth }\end{array}$ & dry mouth \\
\hline
\end{tabular}

brushing tasks in a random order, while Table II provides the final and correct order.

The special education instructors can also activate the audio option of that puzzles so that the children with hearing and verbal understanding abilities can take benefit from this option. They can hear some encouragement messages and get hints for each move they perform. Once the complete solution is reached correctly the children will receive some animated multimedia encouragement. These puzzles will strengthen their self-confidence.

Images, texts, and sounds used in the puzzles are fully customizable. Teachers and parents can take advantages of these features by selecting the appropriate elements specific to the children. The system supports the personalized learning with is the best model for children with special needs.

Different edutainment games are proposed to allow the children to learn in a funny and enjoyable way. Three games were proposed and evaluated in [9]. Another math game was proposed in [11] which allows the children to exercise while learning.

\section{SYSTEM ARCHITECTURE}

Our system is composed of four different modules which are the following: (1) the teacher module; (2) the student module; (3) The server module; (4) the manager module. Fig. 2 gives an overview of the system.

\section{A. The Teacher Module}

This module is used by teachers to present lessons to students and to control the students' computers during class time in order to keep their focus on the lesson. This module allows the teacher to: (a) Share his or her computer screen with each student so they can get a front row seat for the lesson; (b) Lock student's computer keyboard and mouse for more attention; (c) Broad cast multimedia materials to each student's PC; (d) Monitor all students' screens and watch their activities; (e) Access individual student's computer to help him/her during class; (f) Restart, logoff students' computers remotely.

\section{B. The Student Module}

This module is installed on students' computers. It performs the following tasks: (a) Allows student to navigate subjects and lessons, interact with contents, and solve exams during free mode; (b) Communicate with teacher's computer by sending the students response and interaction during control mode; (c) Displays and plays back multi-

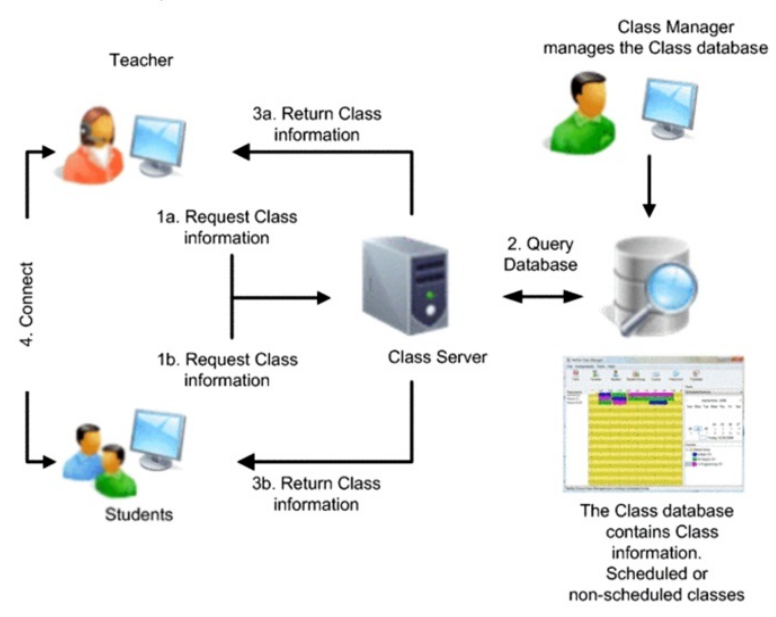

Figure 2. Different modules: teacher, student, server and manager

media materials sent from teacher's computer; (d) Allows student to show off his/her good work to other classmates.

\section{The Manager Module}

The manager module: This module is installed on a server, and provides the following functionalities: (a) Manage subjects and lessons; (b) Assign lessons to plan and to group of students; (c) Manage students, teachers, supervisors, and parents; (d) Control the access of all users type to the system.

\section{CURRICULUM CONTENTS}

The topics cover different subjects based on the Shafallah curriculum and will be delivered through welldesigned interactive multimedia tutorials that reflects the children cultures and customs. The curriculum includes the following topics: mathematics: numbers, simple arithmetic (addition, subtraction, etc.), dealing with money, date and time, measurements and calculation; reading and listening: simple texts and answer the questions about, listening and comprehension, arrangement stories events using pictures, recognizing environmental animals and plants, foods, clothes, safety and personal care, differentiation between objects, social activities (cinema, entertainment, TV, club, etc.), transportation means, community services, using communication devices, cleaning and properties, simple religious concepts, first things first, using the computer machine, dealing with MS-Word and MS-Power Point, email, chatting and the Internet, using tools for special activities, etc. The software will support the instructors to deliver educational materials more effectively. The images proposed in the tutorials are taken from the local environment as shown in the following Fig. 3, 4 and 5.

\section{TANGIBLE USER INTERFACES}

We propose different tangible user interfaces TUIs to improve the learning process and increase the interaction of the children with special needs with the system. These interfaces are described in the following section.

\section{A. TUI with a Magic Stick}

We have presented in [10] an edutainment system that uses multimedia technology to enhance children's learning by displaying different media related to an object once children tap over that object. The system could be inter- 
acted with through a specially designed tangible interface called the Magic Stick (a simple electronic device Bluetooth-based). The system incorporates three different games that help children of various ages acquire knowledge in a fun and easy and enjoyable manner. The evaluations that we have conducted have shown that children grasped the idea of the Magic Stick quickly, and interacted with their peers through discussions and sharing ideas. The system has also encouraged children to pose questions to their teachers regarding the pictures displayed, and consequently, to learn about new entities such as animals and birds. Fig. 6, shows a small child taping on the duck object using the magic stick. The signal will be

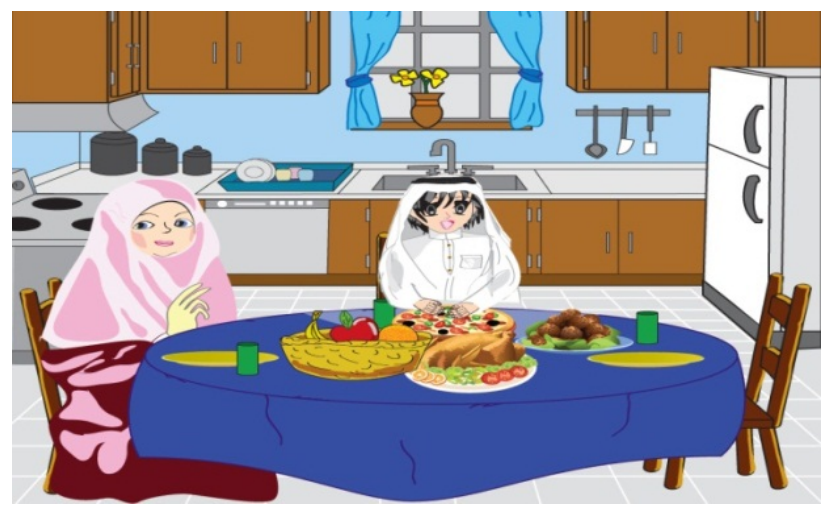

Figure 3. A child is taking dinner with his mother. The image is drawn locally by our designer

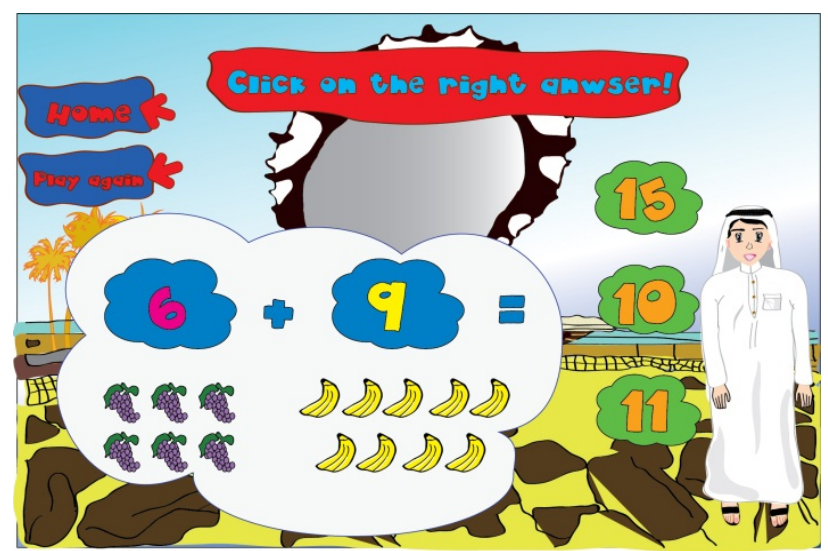

Figure 4. The child should count the objects displayed in the image and select the right answer of the addition operation

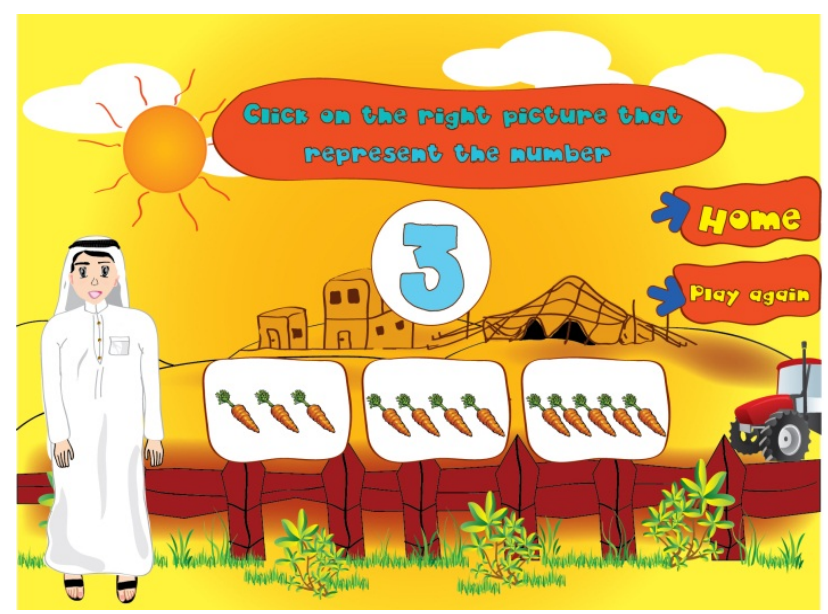

Figure 5. The child should select the right image corresponding to the number 3 sent to the system where the software is running. The system will recognize the taped object and will display more multimedia elements and information about that object. These information can be obtained from our local database or directly from the Internet.

\section{B. TUI with foot Learn-PAD}

We have presented in [10] an exergaming system that allows children to have fun and learn basic math skills while exerting physical strength. Children can interact with the system through a specially designed tangible foot pads interface, called Learn-Pads, which detects and counts the user's footsteps. This interface contributes in overcoming the obesity problem that many children with special needs may face due to their exercising. Our next work will include the development of new video games that enhance the children's knowledge in various topics such as shapes, vocabulary and letters. We will evaluate the Learn-Pads in school/Unit1 and Unit2 in the Shafallah Center to test more its social effects and to scrutinize the role of the system as a learning assistant to the teacher. In addition, we are planning to incorporate a logic engine module that plays the role of a personal trainer and controls the intensity of the games based on the heart rate of the users. Finally, the foot pads will be enhanced with vibrotactile actuators in order to add more fun to the games.

\section{TUI with Lenovo IdeaPAD}

In this work [2], we presented a system with Lenovo IdeaPAD. The system allows the children to learn about new objects and entities, by simply selecting them from the IdeaPAD device. These objects are from the local environment and can be updated whenever necessary. The children learn also about how to initiate and complete a given activity based on the previous selected objects. These activities include: (1) the school day activity, from

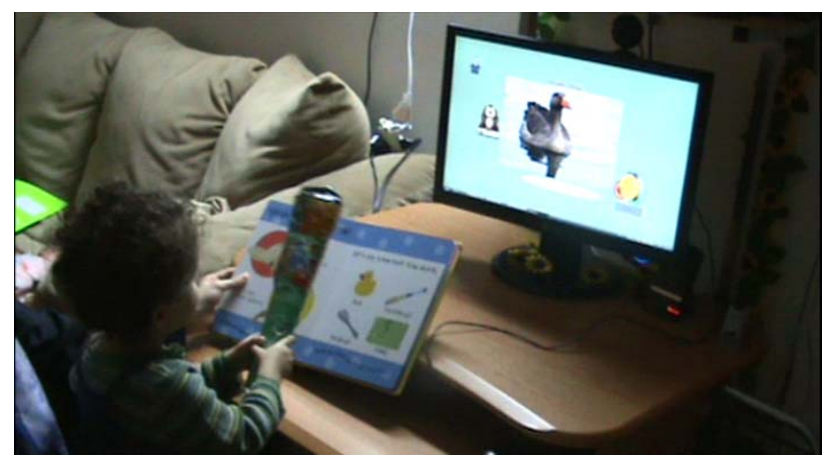

Figure 6. A child is taping on the picture of a Duck

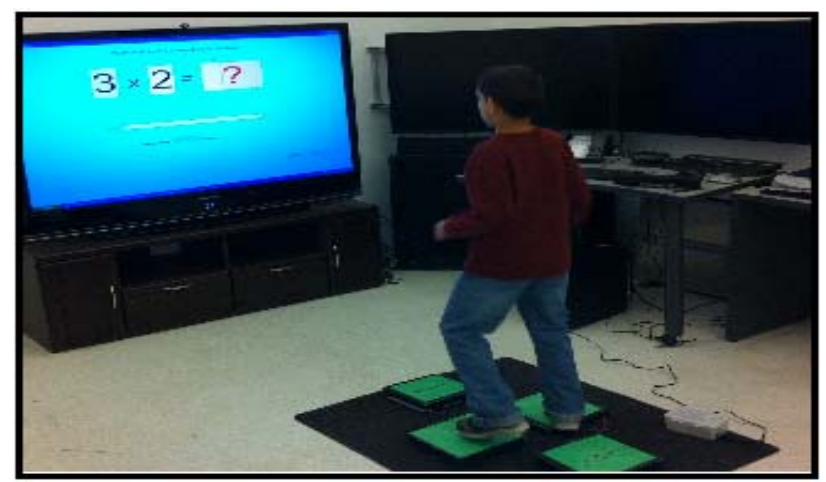

Figure 7. A child is exercising with foot learn-pads 
getting up in the morning to going to bed in the evening, (2) the brushing activity, what are the steps to follow to initiate and complete this activity, etc. The output of the system is delivered as a set of appropriate multimedia representations related to the objects being selected. During class time, learning can be achieved either as a whole class or independently. The teacher can use his/her laptop to direct the lesson's multimedia to the smart board device in front of the children in order to show them the activity and guide them on how to interact with the lesson. On the other hand, the teacher can assign to each child an independent activity on his/her IdeaPad and ask him/her to initiate and complete the activity. Lessons and children's performance are accumulatively saved on the children' IdeaPad which will be carried with them to their homes. Parents can track their children's progress and be more engaged in the learning process. They can help their children to review their lessons for do more practices. The children can also use their ideaPAD alone at home and get prompted on all the steps to perform a given daily-living activity. The children will be more proactive during the learning session and also at home. This approach will increases the children's self-reliance and self-dependence. Fig. 8 shows the proposed system with the different components: the smart board, the main server, the teacher's laptop and the children's Lenovo IdeaPAD smart devices.

The proposed TUIs improve the one way learning model and allow the children, parents and teachers to interact as depicted in Fig. 9.

The proposed edutainment games that may involve two or more children in the play will also improve the one way learning model as shown in Fig. 10.

\section{KNOWLEDGE EXTRACTION FROM TEXT}

Formal concepts have been introduced by WILLE [16] and were applied in different areas of science like psychology, sociology, anthropology, medicine, biology, linguistics and computer sciences. A strong feature of Formal Concept is its capability of producing graphical visualizations of the inherent structures among data. We have developed many tools to summarize English and Arabic text without using semantic rules [9]. In fact, we build concept lattices based on concept analysis and Galois connection to extract the meaningful knowledge from a text (called also best concepts). The purpose of this work is to allow the children surfing the Internet and understand relatively the text in the websites. We take the text from the desired website and extract the main keywords. This list of keywords will be matched with the corresponding, images, sounds, clips either from a local database or simply from the Internet. The database is enhanced regularly by keywords and related multimedia elements. We associate with every keyword, the list of synonymous words, and whenever the keyword represent an object, we associate it that keyword some multimedia elements. For instance, if the key word is a duck or a fish or a country name, the child can get images, sounds and short clips associated with these object.

\section{System AND TUTORIALS EVALUATION}

We evaluate the tutorials through a developmental study which consists of conducting a series of surveys. This includes the following:

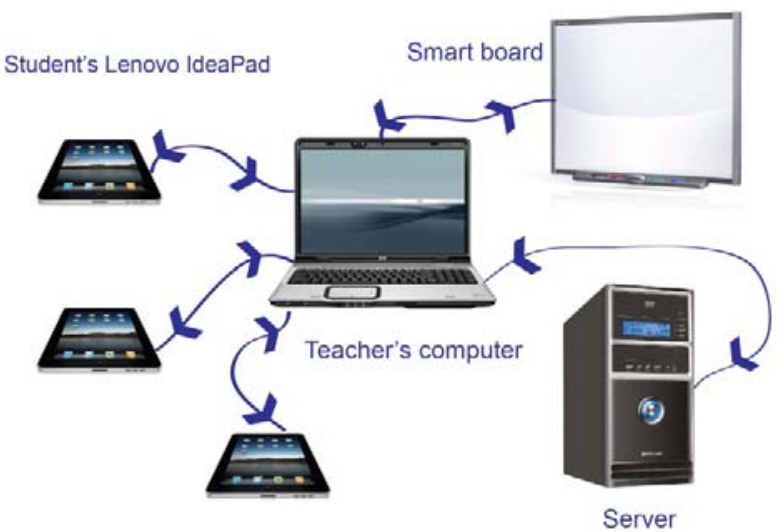

Figure 8. The main components of the proposed system

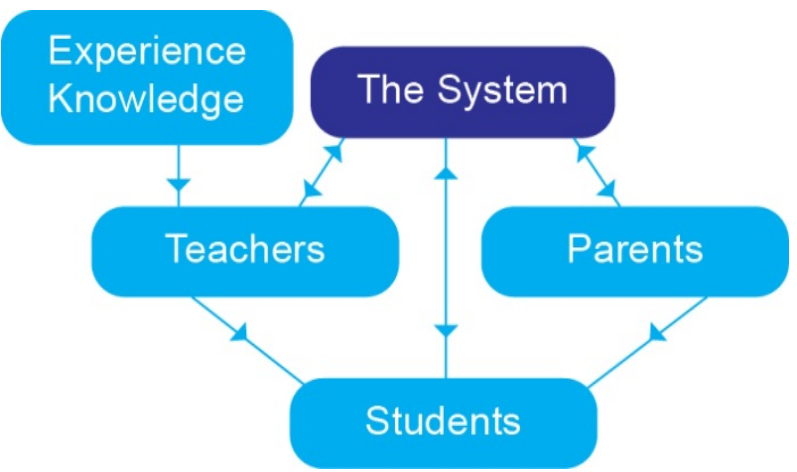

Figure 9. The system contributes to the improvement of the classical one way learning model and allows the children to be more proactive

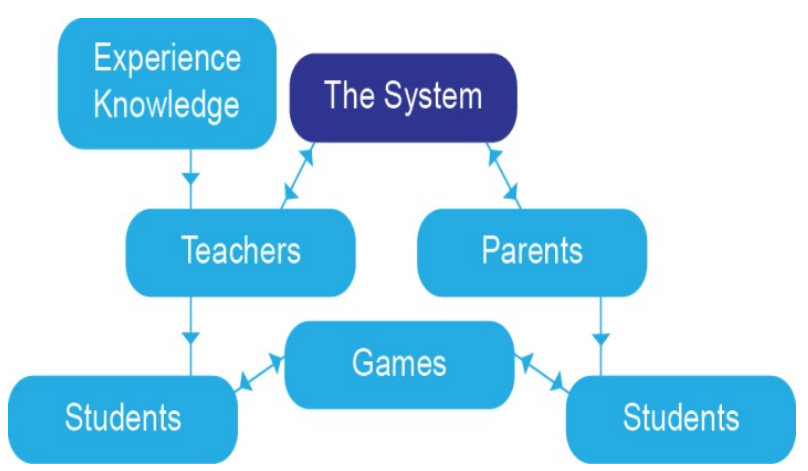

Figure 10. The edutainment games that involve many children contribute to the improvement of the classical one way learning model.

\section{A. Trend Study}

All the children participating in learning through the designed and developed tutorials are surveyed. We will then analyze the data and study the trend of improvement in general.

\section{B. Cohort Study}

The students' performance will be monitored over the project's duration and sampled every 3-4 weeks for analysis in order to give us an indication of the progress and feedback on the redesign process of the tutorial.

\section{Panel Study}

Two identical groups of students will be followed up throughout the life time of this project. One group will be studying according to our proposed tutorial and the other group without it. We will then evaluate the progress of both group in an objective way. As shown in table III. 
TABLE III.

TUTORIALS EVALUATION MATRIX

\begin{tabular}{|c|c|c|c|c|c|c|c|}
\hline & $\begin{array}{l}\text { (1) In } \\
\text { (3) } \mathrm{Ol} \\
\text { (6) } \mathrm{Le}\end{array}$ & $\begin{array}{l}\text { rview } \\
\text { ervati } \\
\text { ner I }\end{array}$ & $\begin{array}{l}\mathrm{s} ; \mathrm{s} \\
\mathrm{s} ;(7 \\
\end{array}$ & $\begin{array}{l}\text { r; (2) } \\
\text { ests; } \\
\text { earne }\end{array}$ & $\begin{array}{l}\text { 1struc } \\
\text { Pare } \\
\text { Quest } \\
\end{array}$ & $\begin{array}{l}\text { Inter } \\
\text { Inter } \\
\text { Inaire }\end{array}$ & $\begin{array}{l}\text { ews; } \\
\text { ews; }\end{array}$ \\
\hline $\begin{array}{c}\text { Some Evaluation } \\
\text { Questions }\end{array}$ & (1) & (2) & (3) & (4) & (5) & (6) & (7) \\
\hline $\begin{array}{l}\text { a. What knowledge } \\
\text { was learned by } \\
\text { participants? }\end{array}$ & & & & & & & \\
\hline $\begin{array}{l}\text { b. What skills were } \\
\text { developed by } \\
\text { learners? }\end{array}$ & & & & & & & \\
\hline $\begin{array}{l}\text { c. What attitudes } \\
\text { were formed by } \\
\text { learners? }\end{array}$ & & & & & & & \\
\hline $\begin{array}{l}\text { d. What were } \\
\text { learner reactions to } \\
\text { the multimedia } \\
\text { interface? }\end{array}$ & & & & & & & \\
\hline $\begin{array}{l}\text { e. What were in- } \\
\text { structor reactions } \\
\text { to the multimedia } \\
\text { interface? }\end{array}$ & & & & & & & \\
\hline
\end{tabular}

We will be also doing human computer interaction usability studies as explained below.

\section{At the Desgin Stage: Storyboarding and UML Diagram}

Traditionally, storyboarding was used in the film industry, particularly in animation, to illustrate the flow of a story in picture form. However, this technique can be used to illustrate navigation in an application by drawing a series of screens. This is also useful for highlighting the needed interaction elements.

\section{E. At the early prototyping stage (User Interface Heuristic Evaluation and Data Mapping/Object Model)}

Each screen (and the navigation from screen to screen) is evaluated against a list of heuristics and any problems noted. This is repeated and the problems recorded.

\section{F. At the End/delivery stage (Observation in the Workplace)}

The best way to find out about a system, its users, and how they interact, is to observe the system in context, i.e. in the workplace. Observations such as these should deliver accurate, natural data for evaluating prototypes or delivered systems. We intend to use video tapped sittings and evaluate them.

The system design and interfaces are evaluated using the following criteria.

\section{G. Usability}

Is the system providing a coherent and flexible user interface that can be used easily with all users? Has the system an obvious component which allows the user to navigate easily? Are the tutorials easy to use by teachers, parents and children? Is the system adaptive to user needs? Is the tracking component working properly and produce the expected results?

\section{H. Supportability}

Can the system be easily modified or extended easily? Can teachers and parents add materials easily?

\section{Contents and Desgin}

Are the design and contents of the tutorials and puzzles satisfactory to children, teachers and parents? What are their feedbacks? Do the tutorials cover well the topics? Are they useful and meet their goals? Quality of texts, images, sounds, and clips? We will compare the progress of students.

\section{J. Performance}

Are the performance requirement concerned with quantifiable attributes of the system, such as response time, throughput availability and accuracy?

\section{K. Flexibility}

Since it will be used regularly with a new set of initial data and can accommodate changes in database such as modifying the contents, is the system flexible?

\section{Security}

Is the system preventing unauthorized users to access the system?

The quality of special education depends on the quality of assessment information and its timely application in the classroom, school and community to prescribe practices and monitor programs and services. We know that the indicators of intelligence are mainly based on the ability to think logically, to use stored knowledge to solve problems, to reason by analogy, and to extend or extrapolate knowledge to new situations. So the system provides us with assessment module based on logic, language, spatial representation, use of the body, social competence. The main strengths of the system are features and functions which can be described briefly as follows:

(1) Easy to use and self-administration, (2) Software control of item presentation, (3) Response evaluation based on conceptual models or algorithms, (4) Decision making based on rules and criteria, (5) Assess and evaluate the progress of individual children, (6) Test of Nonverbal Intelligence for children with communication challenges which requires no reading, writing, or speaking, (7) Some tests require that the child have adequate verbal abilities to answer the questions it includes verbal, arithmetic, picture completion and object assembly, (8) Students entering their responses by simply touching a computer screen.

The assessment tools will contribute in the elimination of the misplacement of student as a result of poor evaluation which can have bad results for both student and teacher, since misplaced students tend to lose interest. The system provides a more holistic evaluation of students in different contexts. The most widely used form of assessment is a direct observation of the student in a classroom setting. Direct observations, along with scores from both achievements and tests are good evaluation methods, but very time consuming, so a big waiting list for evaluation. This lag time is very discouraging to many classroom teachers, diagnosticians, and students and parents. Our computer-based assessment tool can speed up the entire process as computers store and compute test results. We can store and manage large data sets that can be easily accessed by school personnel, parents and practitioners. The system will allow a greater volume of information to be handled by fewer personnel, to better serve the needs of students, to comply with ever changes, and to manage and evaluate special education programs. We integrated in the 
system text, graphics, audio and video in order to give more comprehensive evaluations, so that students with special needs will become more familiar and comfortable. Interactive methods of assessments will help students to learn according to their individual needs and skills. Teachers, administrators, students and parents will also benefit from the system concerning evaluation. This formulates a real-time picture of students in everyday life situations that allows a full view of students' abilities, so that skill deficits that occur during different tasks are more quickly and easily identified. The system is designed to monitor student's progress. It provides teachers with a virtually real-time picture on which students need help, where they need it, and how the teachers can help best. The system can also monitor the student's performance throughout a portion of the curriculum which is a perfect way for teachers to catch and address gaps in a student's knowledge or learning and provides them with the opportunity to learn more effectively. Teachers can use the assessment to gauge how well they are teaching based on the student's needs over time. For instance, if a first assessment reveals a particular student is at risk of failing in a particular subject, a teacher can reassess him or her for a second time to see if changes might help. If the student shows progress, the teacher can note what kind of approach of learning works best. If the student demonstrates little or no progress, the teacher knows it's time to try something else.

The system is designed specifically for teachers and students; each component has a simple, intuitive interface that makes it easy to get started right away. The system also makes it easy for students to have more control over their own learning and to get the maximum benefit from the technology. The system assessment offers many facilities, such as numerical and symbolic answers, and negative mark for wrong answer. The assessment is a useful tool that enables teachers to conduct more frequent, detailed, consistent, and stable assessments of student. The system offers teachers an easy and effective way to discover how well each student understands the lesson. It can also offer quizzes or planned tests enhanced with images and multimedia content. By using the software, students can easily respond to questions, and teachers can instantly see the results which are automatically recorded in the student database. Finally, the teacher, parents, and administrators can log in through secure, password-protected access to view summary reports and analyses. These reports give them a "photo album" of the student's growth and indicate which students needs extra help, and give ideas on how they can encourage students to better serve their needs.

The system offer tools to teachers to access, view and manage all assessment data from one location. Teachers can design questions using six different types - true or false, yes or no, multiple choice, multiple answer, numeric response and short answer. They can also deliver interactive assessments that provide instant responses so that they know when to review a concept or give students extra help. In addition, teachers can keep the students focused on learning because they can get a thumbnail view of each computer screen in the class. Different assessment strategies can be used to support positive behavior and monitor progress at the level of the student, the classroom, or the entire school.
The benefits of computerized forms of assessment like "Quizzes” with automatic marking and feedback on progress are as follows: (1) Various question types, e.g. multiple choice. (2) Response options, e.g. multiple attempts. (3) Student feedback, e.g. give correct answer. (4) Staff feedback: detailed performance. (5) Test motivated them to understand the content. (6) Provide correct answers to quiz questions after first attempts. (7) Students are rewarded for choosing positive solutions.

It is worth nothing that the Software can be used in two different modes:

Control mode: During a specific learning session, the instructor can control the software by activating only the required lesson in order to keep the students focused on the current one only. The students will not be able to access other lessons or subjects using his smart device.

Free mode: In this mode, the students can access different materials and lessons, but only those included in the timely plan which are set by the instructor.

\section{CONCLUSION AND FUTURE WORKS}

The project focuses on innovative practices directly related to children with MID-MLD. It addresses the teaching problem by interacting with active module throughout the course. The system provides a direct link of interactions between the static content (text, images) and the dynamic content (animations and games), and in doing usability studies on the different proposed tangible user interfaces of the system so that we do not develop just yet another tool. Note that, when designing a tutorial for children with MID-MLD, one might think to base it mainly on the ordinary curriculum that is taught in normal schools. We can then use the text and add some interactive animations and we are done. However, these children need effectively specific treatment and deep care. In order to improve the understanding of the children with MID-MLD, the tutorials should try to attract the maximum number of the children's senses. For instance, in addition to seeing, hearing and eventually reading, the children with MIDMLD should taste and touch the corresponding items whenever possible. If we want to teach a child with MIDMLD the concept of "coldness", then drinking cold water and touching ice would highly increase his/her understanding. A database is dedicated to every child. It contains the objects that the child's has learned. When proposing a puzzle or an activity, the images will be from the child's associated database.

We found also the children can learn more quickly whenever the images used in the tutorials are from their local environment. When deciding on how to use information and communication technology to support children with MID-MLD it is essential first to find the things they are able to do and/or what they have difficulty with.

As future work, we plan to develop new edutainment games, puzzles using new TUIs suitable for more categories of children with special needs. We will continue conducting deep analytical studies to evaluate the performance of the children in learning using the proposed TUIs and the multimedia elements. A web-based components will be added to the system. It will allows parent to follow up their children progress online and also communicate with the instructors. 


\section{REFERENCES}

[1] S.I. Al-Gain and S.S. Al-Abdulwahab, "Issues and Obstacles in Disability Research in Saudi Arabia”, In Asia Pacific Disability Rehabilitation Journal, vol. 13, no. 1, 2002.

[2] S. AlHazbi, J. M. Alja'am, M. Saleh, A.M. Jaoua, M.S. Solaiman, T. AlHomri, A. Alkhatib and A. El Saddik, "An Assistive Computerized System for Managing and Educating Children with Moderate and Mild Intellectual Disabilities at Shafallah Center in The State of Qatar (in Arabic)”, In Proceedings of the Seventh International Computing Conference in Arabic, ICCA'2011, Riyadh, Kingdom of Saudi Arabia, May 31 - June 2, 2011. Unpublished.

[3] S. Alper and S. Raharinirina, "Assistive Technology for Individuals with Disabilities: A Review and Synthesis of the Literature", Journal of Special Education Technology, 21(2), pp. 47-65, 2006.

[4] AmlVital Spanish Project, "Intelligent Communication Devices for Elderly and Disabled People”, (2007) http://www.innovationsreport.com/html/reports/communication_media/report-84220.html

[5] Batshaw M.L, "Children with Disabilities", 4th edition, Baltimore, MD: Paul H. Brookes Publishing Co.; 1997.

[6] J. Chelin, L. Kosseim, and T. Radhakrishnan, "Using Natural Language Processing to Assist the Visually Handicapped in Writing Compositions”, Canadian AI 2006, LNAI 4013, pp. 300-311, 2006.

[7] H. Guillermo, N. Jaganjac, and J. Beal, “A Note on Disability in the Middle East and North Africa”, Document of the World Bank, Final report, June 30, 2005.

[8] A. Jaoua, W. Lebda, and J.M. Alja’am, “Automatic Structuring of Search Results of Arabic and English Meta-Search Engines by Formal Concepts Extraction", in International Journal of Computer Science and Engineering in Arabic, Philips Publishing Company, vol. 3, no. 1, 2009.

[9] M. Jemni and O. Elghoul, "Towards Web-Based Automatic Interpretation of Written Text to Sign Language”, In Proceedings of ICTA’07, April 12-14, Hammamet, Tunisia, pp. 43-48, 2007.

[10] A. Karime, M. Anwar Hossain, A. El Saddik, and W. Gueaieb, “A Multimedia-Driven Ambient Edutainment System for the Young Children”, In Proceedings of the ACM Workshop on Story, Representation Mechanism and Context, ACM SRMC, Oct. 2008. Vancouver, Canada.

[11] A. Karime, M. Anwar Hossain, ASM Mahfujur Rahman, W. Gueaieb, J. M. Alja'am, and A. El Saddik, "RFID-Based Interactive Multimedia System for the Children”, In International Journal of Multimedia Tools and Applications, SPRINGER, (ISSN: 13807501, Print Version, Journal no. 11042, DOI: 10.1007/s11042011-0768-3), March 2011, in press.

[12] A. Karime, H. Al Osman, W. Gueaieb, J. M. Alja'am, and A. El Saddik, "Learn-Pads: A Mathematical Exergraming System for Children's Physical and Mental Well-Being”, In Proceedings of The IEEE International Conference on Multimedia and Expo, ICME2011, Spain, July 2011, in press.
[13] L. Mechling, “Assistive Technology as a Self-Management Tool for Prompting Students with Intellectual Disabilities to Initiate and Complete Daily Tasks: A Literature Review”, In Education and Training in Developmental Disabilities, 42(3), pp. 252-269, 2007.

[14] G.S. Neil,, "Project Archimedes at Stanford University", http://archimedes.standford.edu.

[15] R. Smith, "Children with Mental Retardation: A parents' Guide”, Rockville, MD: Woodbine House; 1993.

[16] R. Wille, "Restructuring Lattice Theory: An Approach Based on Hierarchies of Concepts”, In I. Rival (ed.), Ordered Sets. pp. 445470. Reidel, Dordrecht-Boston M. Young, The Technical Writer's Handbook. Mill Valley, CA: University Science, 1989.

\section{ACKNOWLEDGMENT}

The authors would like to thank deeply Qatar University, Qatar Foundation and the Shafallah Center for children with special needs, in Doha, Qatar for all the supports to conduct this research work.

\section{AUTHORS}

J. M. Alja'am is with the Department of Computer Science and Engineering at Qatar University, Doha, Qatar (e-mail: jaam@qu.edu.qa).

A. M. Jaoua is with the Department of Computer Science and Engineering at Qatar University, Doha, Qatar (email: jaoua@qu.edu.qa).

S. Alhazbi is with the Department of Computer Science and Engineering at Qatar University, Doha, Qatar (e-mail: salhazbi@qu.edu.qa).

A. Hasnah is the Department of Computer Science and Engineering at Qatar University and with Qatar Foundation, Education Division, Doha, Qatar (eahasnah@qf.org.qa).

A. Karime is with the School of Information Technology and Engineering at the University of Ottawa, Canada (e-mail: ali@mcrlab.uottawa.ca)

A. Elsaddik is with the School of Information Technology and Engineering at the University of Ottawa, Canada (e-mail: abed@mcrlab.uottawa.ca)

This article is an extended version of a paper presented at the IEEE EDUCON20211 Conference, held from April 4th-6th, 2011, in Amman, Jordan. Received, January $17^{\text {th }}$, 2011. Published as resubmitted by the authors on May $2^{\text {nd }}, 2011$. 